\title{
Yersinia enterocolitica: its isolation by cold enrichment from patients and healthy subjects
}

\author{
R VAN NOYEN,* J VANDEPITTE, $\dagger$ G WAUTERS $\ddagger$ R SELDERSLAGHS* \\ From the *Department of Clinical Pathology, Imelda Hospital, B-2820 Bonheiden, the †Department of \\ Microbiology, St Raphaël University Hospital, B-3000 Leuven, and the $\ddagger$ Department of Microbiology, \\ Cliniques Universitaires St Luc, B-1200 Brussels, Belgium
}

SUMMARY Routine culture and cold enrichment were compared in a prospective study on the isolation of Yersinia enterocolitica from patients with intestinal disease. Healthy controls were examined with the cold enrichment method only.

$Y$ enterocolitica was isolated from $5.9 \%$ of 1635 patient stools, $3.4 \%$ of 206 appendices, and $4.0 \%$ of 555 control stools. Serotypes 0:3 and 0:9 were eight times more prevalent in patients than in controls. Other serotypes were twice as prevalent in controls than in patients. Cold enrichment did not significantly increase the recovery of serotypes $0: 3$ and $0: 9$ in acute enteritis, but it was responsible for all isolates of the other serotypes. Evidence is presented that the other serotypes are not pathogenic. In patient stools, $Y$ enterocolitica was demonstrated less frequently than Salmonella $(9 \cdot 1 \%)$, and more often than Campylobacter jejuni $(1 \cdot 8 \%)$ and Shigella $(0 \cdot 1 \%)$.

Yersinia enterocolitica was described more than forty years ago, ${ }^{1}$ but it is only in the last decade that this organism has emerged as a frequent pathogen. In many European countries, particularly in Belgium and Scandinavia, $Y$ enterocolitica is second only to Salmonella as an aetiological agent of bacterial gastroenteritis. In these and most other countries, among the great number of known serotypes, only types $0: 3$ and $0: 9$ are regularly associated with disease in man.

Even now, $Y$ enterocolitica is rare or unknown in many parts of the world, particularly in developing countries; this could be explained, perhaps, by the lack of detection facilities and trained personnel. It is more difficult, however, to explain its apparent rarity in highly developed countries where technical skill and awareness of the organism should promote its isolation. This is all the more puzzling for countries such as France and the USA, which have a common border respectively with Belgium and Canada, two countries where $Y$ enterocolitica is frequently isolated. Such differences have often been accounted for by the inadequacy of techniques for routine stool culture in diagnostic laboratories. Although the identification of Yersinia should pose no problem for the informed bacteriologist, there is a widespread belief that its isolation from stools is

Accepted for publication 18 February 1981 delicate and requires special media and low incuba tion temperatures. There have been enthusiastic reports on the use of cold enrichment in buffer or broth, a procedure which is unpractical for clinical diagnosis, since the recovery of Yersinia may then require several weeks.

In a recent study we have demonstrated ${ }^{2}$ that the addition of cold enrichment to routine stool cultures resulted in an increase in the recovery of $Y$ enterocolitica from patients' stools. However, all the strains that were exclusively grown from cold enrichment, belonged to serotypes other than the common human serotypes $0: 3$ and $0: 9$. We presented evidence that these types were not pathogenic and that cold enrichment was of no value in the diagnosis of patients with acute enteritis.

At the same time two other groups of investigators published rather different results and stressed the efficacy of, and the need for, cold enrichment. ${ }^{34}$ Although differences in methodology, patient material, and epidemiological setting could explain this apparent contradiction between the North American and our own results, we decided to repeat and extend our investigation in a controlled prospective study, including a group of healthy subjects.

\section{Material and methods}

The survey was conducted during the whole year 1052 
1979 in the routine laboratory of a 250 -bed general hospital where a monthly average of 140 stool cultures are performed for in- and outpatients.

The material examined could be divided in three groups:

1 Routine stool cultures (1635) from patients with diarrhoea or other gastrointestinal complaints. This group included a few specimens from healthy family members or ward contacts of patients with positive stools.

2 Specimens of appendix (206) from patients operated with a diagnosis of acute appendicitis.

3 Healthy controls (555). This group comprised 341 adult factory workers and 214 school children and students, aged between 3 and $20 \mathrm{yr}$. Both sexes were almost equally represented. Subjects came from 60 different localities.

The isolation procedure was identical for the two patient groups. Stools or appendicular contents were plated on MacConkey and Salmonella-Shigella (SS) agar (Difco) and read after overnight incubation at $37^{\circ} \mathrm{C}$. A second reading was performed after a further $24 \mathrm{~h}$ at room temperature $\left(20^{\circ} \mathrm{C}\right)$. A loopful was also inoculated into:

1 Selenite broth (Difco) $(10 \mathrm{ml})$ supplemented with $40 \mathrm{mg} / \mathrm{l}$ novobiocin, with subculture after $18 \mathrm{~h}$ at $37^{\circ} \mathrm{C}$ on to SS agar.

2 Rappaport broth $(5 \mathrm{ml})$ for Salmonella (Merck) with overnight incubation at $37^{\circ} \mathrm{C}$ and subculture on brilliant green agar (BBL).
3 Modified Rappaport broth $(5 \mathrm{ml})$ for Yersinia according to Wauters, ${ }^{5}$ incubated at room temperature for $48 \mathrm{~h}$ and followed by plating on to SS agar.

4 Sterile $1 / 15 M$ phosphate buffer $(10 \mathrm{ml}) \mathrm{pH} 7 \cdot 6$, incubated in a refrigerator $\left(4^{\circ} \mathrm{C}\right)$ with transfer after three weeks on to MacConkey and SS agar. Previous experience had shown that 3 weeks enrichment was sufficient for optimal recovery of Yersinia.

After subinoculation all solid media were incubated and read as the direct plating media and suspect colonies were subcultured on Kligler and triple sugar iron (TSI) slants and identified by conventional methods. Special attention was given to small lactose-negative colonies. Biotyping and serotyping were performed according to the scheme of Wauters. ${ }^{6}$

All patients' specimens were also examined for the presence of Campylobacter jejuni by streaking a diluted suspension on to Columbia agar (Difco) enriched with $5 \%$ horse blood and rendered selective by the addition of the antibiotic supplement according to Butzler (Oxoid SR85). Incubation was $48 \mathrm{~h}$ in a Gaspak jar using a hydrogen generator without catalyst.? The stools of the healthy controls were only examined after cold enrichment following the same technique as used for patients.

In a number of subjects infected with $Y$ enterocolitica, agglutinating serum antibodies were titrated against an unheated suspension of their own organism, used as antigen..$^{5}$ Agglutination was read under a magnifying lens after overnight incubation at $37^{\circ} \mathrm{C}$

Table 1 Number (and percentage) of isolates of pathogenic bacteria from patient stools and appendixes during 1979

\begin{tabular}{|c|c|c|c|c|}
\hline \multirow[t]{3}{*}{ Organism } & \multicolumn{4}{|c|}{ Type of specimen } \\
\hline & \multicolumn{2}{|c|}{ Stools $(n=1635)$} & \multicolumn{2}{|c|}{ Appendix $(\mathrm{n}=206)$} \\
\hline & No & $\%$ & No & $\%$ \\
\hline $\begin{array}{l}\text { Y enterocolitica all serotypes } \\
\text { serotypes } 0: 3 \text { and } 0: 9 \\
\text { other serotypes } \\
\text { Salmonella } \\
\text { Shigella } \\
\text { Campylobacter jejuni }\end{array}$ & $\begin{array}{l}97(12)^{*} \\
67(12) \\
30 \\
149 \\
2 \\
30\end{array}$ & $\begin{array}{l}5 \cdot 9 \\
4 \cdot 1 \\
1 \cdot 8 \\
9 \cdot 1 \\
0 \cdot 1 \\
1 \cdot 8\end{array}$ & $\begin{array}{l}7 \\
7 \\
0 \\
6 \\
0 \\
2\end{array}$ & $\begin{array}{l}3 \cdot 4 \\
3 \cdot 4 \\
0 \\
2 \cdot 9 \\
0 \\
1 \cdot 0\end{array}$ \\
\hline
\end{tabular}

* Reisolations from the same patient.

Table 2 Number of patients with Yersinia-positive stools according to clinical findings and serotype

\begin{tabular}{|c|c|c|c|c|c|}
\hline \multirow[t]{2}{*}{ Clinical presentation } & \multicolumn{4}{|l|}{ Serotypes } & \multirow[t]{2}{*}{ Total } \\
\hline & $0: 3$ or $0: 9$ & & Others & $0: 3$ or $0: 9$ and others & \\
\hline $\begin{array}{l}\text { Enteritis } \\
\text { Appendicular syndrome } \\
\text { Fever } \\
\text { Polyarthritis } \\
\text { Vague non-specific complaints } \\
\text { No symptoms }\end{array}$ & $\left.\begin{array}{l}30(7) * \\
13(1) \\
1(1) \\
1 \\
3 \\
5(1)\end{array}\right\}$ & $\begin{array}{l}t \\
t\end{array}$ & $\left\{\begin{array}{c}7(4) \\
1 \\
0 \\
0 \\
10(1) \\
9(1)\end{array}\right.$ & $\begin{array}{l}1 \\
0 \\
0 \\
0 \\
1 \\
0\end{array}$ & $\begin{array}{r}38 \\
14 \\
1 \\
1 \\
14 \\
14\end{array}$ \\
\hline Total & $53(10)$ & & $27(6)$ & 2 & 82 \\
\hline
\end{tabular}

*Associated with other bacterial pathogens.

+Difference between serotypes 0:3 and 0:9 and other serotypes highly significant when comparing "specific" against non-specific or asymptomatic presentation $(p<0.01)$. 
Results

Table 1 shows the number and percentage of pathogenic bacteria isolated from patient specimens. The number of patients was somewhat lower than the number of isolates due to the reisolation of the same Yersinia strain in 12 convalescent patients. In three patients, two different serotypes of $Y$ enterocolitica were isolated from the same stool specimen.

Overall, 278 bacterial pathogens were isolated from 1635 stool specimens, representing 17 pathogens per 100 stools, excluding enteropathogenic Escherichia coli. Appendixes were positive less frequently: 15 pathogens in 206 specimens $(7 \cdot 3 \%)$.

The clinical presentation of the infection, according to the serotypes of Yersinia, appears in Table 2. There were 82 patients with one or more cultures positive for Yersinia. The great majority $(81 \cdot 1 \%)$ of serotypes 0:3 and 0:9 strains were associated with enteritis or an appendicular pain syndrome, and the reverse was true for strains of other serotypes: $70.3 \%$ came from asymptomatic contacts or from subjects with non-specific gastrointestinal complaints. This difference was highly significant $(p=<0.01)$.

Table 3 compares the number and percentages of isolates that were recovered respectively by the combination of routine culture media and by cold enrichment in buffer. It appears that $80.6 \%$ of $0: 3$ and 0:9 isolates were recovered from the routine media, against none of the other serotypes. The latter were exclusively recovered from cold enrichment.

Table 3 Number and percentage of Yersinia isolates from patient stools according to isolation technique

\begin{tabular}{lcccc}
\hline $\begin{array}{l}\text { Isolotion technique } \\
\text { * Serotype 0:3 or } 0: 9 \%\end{array}$ & Other serotypes & $\%$ \\
\hline $\begin{array}{l}\text { Routine and cold } \\
\text { enrichment positive }\end{array}$ & 50 & 74.6 & 0 & \\
$\begin{array}{l}\text { Only routine } \\
\text { culture positive }\end{array}$ & 4 & 6.0 & 0 & \\
$\begin{array}{l}\text { Only cold } \\
\text { enrichment positive }\end{array}$ & 13 & 19.4 & 30 & 100 \\
All isolates & 67 & 100 & 30 & 100 \\
\hline
\end{tabular}

*Combination of MacConkey, Salmonella-Shigella, modified Rappaport, and selenite media.

Table 4 shows the number and percentages of Yersinia isolates from the 555 healthy controls. While serotype 0:3 and 0:9 comprised $69 \%$ of isolates from patients, their proportion was only $13.6 \%$ of strains isolated from healthy subjects.

All the 22 carriers of Yersinia in the control group were available for interview and medical examination. Two school children with serotype 0:3 and serotype 0:9 positive stool admitted to having a mild diarrhoea, and an adult with the latter serotype complained of polyarthritis and abdominal discomfort. In contrast, nothing abnormal was noted in the 19 carriers of other serotypes, with the exception of vague non-specific digestive complaints in one of them.

Table 4 Number and percentage of Yersinia isolates in 555 healthy control subjects according to serotypes

\begin{tabular}{lll}
\hline Serotypes & No of subjects & $\%$ \\
\hline $0: 3$ & 1 \\
$0: 9$ & $2\}$ & 0.5 \\
Other types & 19 & 3.4 \\
All types & 22 & $4 \cdot 0$ \\
\hline
\end{tabular}

Serum from nine convalescent patients and 12 healthy carriers was available for titration of agglutinins against the infecting organism. The results show that only patients infected with serotype $0: 3$ or $0: 9$ possessed significant antibody titres (Table 5).

Serotypes and biotypes of the Yersinia isolates from stools of patients and controls are listed in Table 6.

Table 5 Number of subjects with agglutinins against their own isolate of Yersinia

\begin{tabular}{llll}
\hline Subject group & Serotype $0: 3$ or $0: 9$ & Other serotypes \\
\hline Patients $(\mathrm{n}=9)$ & $* 5 / 5+$ & $\ddagger 0 / 4$ & $0 / 12$ \\
Healthy controls $(\mathrm{n}=12)$ & - & $0 / 16$ & \\
All subjects $(\mathrm{n}=21)$ & $5 / 5$ &
\end{tabular}

*No with antibody titre $>1 / 800$.

†No examined.

$\ddagger$ No with antibody titre $\geqslant 100$

Table 6 Serotypes and biotypes of Y enterocolitica and related organisms isolated from stools of patients and healthy subjects

\begin{tabular}{|c|c|c|c|}
\hline \multirow[t]{2}{*}{ Serotype } & \multirow[t]{2}{*}{ Biotype or species } & \multicolumn{2}{|c|}{ No of isolatest } \\
\hline & & $\begin{array}{l}\text { from patients } \\
(n=85)\end{array}$ & $\begin{array}{l}\text { from controls } \\
(n=22)\end{array}$ \\
\hline $0: 3$ & 4 & 41 & 1 \\
\hline $0: 9$ & 2 & 14 & 2 \\
\hline $0: 5$ & 1 & 7 & 2 \\
\hline $0: 5$ & $Y$ frederiksenii & 1 & \\
\hline $0: 6$ & 1 & 2 & \\
\hline $0: 6,30$ & 1 & 7 & 1 \\
\hline $0: 6,31$ & 1 & & 2 \\
\hline $0: 7,8$ & 1 & 2 & 1 \\
\hline $0: 7,(13)$ & 1 & & 1 \\
\hline $0: 10$ & 1 & & 1 \\
\hline $0: 12,26$ & $Y$ kristensenii & 1 & \\
\hline $0: 14$ & 1 & 1 & \\
\hline $0: 16$ & $Y$ intermedia & 1 & \\
\hline $0: 16$ & $3 \mathbf{A}$ & 1 & \\
\hline $0: 18$ & $Y$ intermedia & & 1 \\
\hline $0: 41,43$ & 1 & 1 & 2 \\
\hline $0: 46$ & 1 & 3 & $\overline{1}$ \\
\hline $0: 49$ & 1 & & 1 \\
\hline $0: 53$ & $Y$ frederiksenii & 1 & \\
\hline $0: 57$ & 1 & & 4 \\
\hline untypable & 1 & 2 & 2 \\
\hline
\end{tabular}

* Provisional 0-factors.

†Excluding reisolations from the same patient 


\section{Discussion}

The high prevalence of Yersinia enterocolitica in stools of patients with gastroenteritis and various digestive complaints has been confirmed. Nearly $6 \%$ were positive, a figure which is higher than previous isolation rates recorded in Belgium and in other countries $^{2}$ and which comes close to the isolation rate of Salmonella, the most frequent bacterial pathogen in stools. However, the increase in isolation rates over earlier figures is partly due to the addition of a large number of non 0:3-non 0:9 serotypes, which were exclusively recovered by cold enrichment.

There is growing evidence, at least in Belgium, that serotypes, other than the common recognised "human" serotypes $0: 3$ and $0: 9$, have no pathogenic potential. A striking difference between the clinical presentation of the "human" and the other serotypes is shown in Table 2. While the former are chiefly isolated from patients with gastroenteritis and abdominal pain syndromes, the latter are significantly more often found in patients with non-specific pathology.

As shown in Table 3, more than $80 \%$ of the recognised human pathogenic serotype $0: 3$ and $0: 9$ strains are recovered with a routine scheme for stool culture comprising MacConkey and SS agar as direct plating media, and selenite and modified Rappaport broth as enrichment. No single isolate was contributed by the inclusion of MacConkey agar and only one was recovered exclusively from selenite broth. The SS + modified Rappaport broth combination therefore seems to satisfy the needs of the diagnostic bacteriologist, as we demonstrated earlier. ${ }^{2}$ The $19.4 \%$ increase of $0: 3$ and $0: 9$ isolates by cold enrichment may justify the routine adoption of this technique. However, a closer look at the 13 strains that were exclusively grown after cold enrichment, reveals that seven were second isolations from convalescent patients, two were from healthy contacts, and one from a patient with polyarthritis. Only three patients with acute Yersinia infection would have been missed by the exclusive use of our routine stool culture technique.

Our findings are in keeping with the conclusions of other investigators ${ }^{3} 8$ that the value of cold enrichment is limited to the detection of Yersinia in convalescent patients, in healthy contacts and in patients with late manifestations of the infection.

As could be expected, the isolation rate of serotypes 0:3 and 0:9 was eight times higher among patients than in healthy controls, even when only the results of cold enrichment were compared $(3.9 \%$ against $0.5 \% ; \mathrm{p}<0.01$ ). This difference would still have been greater if a few "patients" had not been included in the control group.
In contrast, the non 0:3-non 0:9 serotypes were nearly twice as frequent in the stools of controls than in patient stools $(3.4 \%$ against $1.8 \%)$ although the difference was not statistically significant ( $p>0.05$ ). None of the patients or healthy controls harbouring serotypes other than 0:3 and 0:9 had agglutinins against the homologous strain, while the presence of a significant agglutination titre was the rule in patients infected by strains belonging to serotypes $0: 3$ and $0: 9$. This supports the lack of pathogenicity of the "other" serotypes.

As shown in Table 6, the "other" Yersinia show a large number of $\mathbf{0}$-factors, rather evenly distributed between patients and controls. Most of these strains are of biotype 1, but some of them fit into new biochemical groups, mainly known as being from environmental origin. The names $Y$ intermedia and $Y$ frederiksenii were suggested ${ }^{9}$ for rhamnose and melibiose, and rhamnose fermenting strains respectively. Biotype $3 \mathrm{~A}$ was recently described. ${ }^{10}$ For the sucrose-negative strains the specific name $Y$ kristensenii (H Bercovier, personal communication, 1980) has been suggested. It is not surprising that these environmental strains are occasionally found in human stools. It must be emphasised that cold enrichment, though somewhat useless for clinical diagnosis, has proved to be a valuable method for the identification of carriers, for the follow-up of convalescents and for ecological studies of environmental samples and food. However, the presence of serotypes other than 0:3 and 0:9 serotypes and aberrant biotypes in food and the environment should not be interpreted as being of public health importance.

\section{References}

${ }^{1}$ Schleifstein J, Coleman MB. An unidentified microorganism resembling $B$ lignieri and Pasteurella pseudotuberculosis and pathogenic for man. NY State J Med $1939 ; 39: 1749-53$.

2 Van Noyen R, Vandepitte J, Wauters G. Nonvalue of cold enrichment of stools for isolation of Yersinia enterocolitica serotypes 3 and 9 from patients. J Clin Microbiol 1980;11:127-31.

${ }^{3}$ Pai CH, Sorger S, Lafleur L, Lackman L, Marks MI. Efficacy of cold enrichment techniques for recovery of Yersinia enterocolitica from human stools. J Clin Microbiol 1979;9:712-5.

4 Weissfeld AS, Sonnenwirth AC. Yersinia enterocolitica in adults with gastrointestinal disturbances: need for cold enrichment. J Clin Microbiol 1980;11 :196-7.

${ }^{5}$ Wauters G. Diagnostic biologique des infections à Yersinia enterocolitica. Méd Mal Infect 1973;3:437-41.

- Wauters G. Correlation between ecology, biochemical behaviour and antigenic properties of Yersinia enterocolitica. Contrib Microbiol Immunol 1973;2:38-41.

${ }^{7}$ Simmons NA. Isolations of Campylobacters. $\mathrm{Br} \mathrm{Med} \mathrm{J}$ 1977;ii:707.

${ }^{8}$ Ahvonen P. Human yersiniosis in Finland. I Bacteriology and serology. Ann Clin Res 1972;4:30-8. 
- Brenner DJ. Speciation in Yersinia. Contrib Microbiol Immunol 1979;5:33-43.

${ }^{10}$ Bercovier H, Brault J, Barre N, Treignier M, Alonso JM, Mollaret HH. Biochemical, serological, and phage typing characteristics of 459 Yersinia strains isolated from a terrestrial ecosystem. Curr Microbiol 1978;1: 353-7.

\section{The August 1981 issue \\ THE AUGUST 1981 ISSUE CONTAINS THE FOLLOWING PAPERS}

\section{Review article}

Examination of products of conception from previable human pregnancies DI RUSHTON

Histological study of the effects of three antiinflammatory preparations on the gastric mucosa RLE MCINTYRE, MS IRANI, J PIRIS

Rectal biopsy in the diagnosis of systemic vasculitis CR TRIBE, DGI SCOTT, PA BACON

Human intestinal mucosal mast cells: evaluation of fixation and staining techniques S STROBEL, HRP MILLER, ANNE FERGUSON

Immunoperoxidase staining of formalin-fixed, paraffin-embedded, human renal biopsies with a comparison of the peroxidase-antiperoxidase (PAP) and indirect methods RA SINCLAIR, J BURNS, MS DUNNILL

Mucin histochemistry of the columnar epithelium of the oesophagus: a retrospective study JR JASS

Congo-Crimean haemorrhagic fever in Dubai: histopathological studies A BASKERVILLE, AGO SATTI, FA MURPHY, DIH SIMPSON

Cerebral malakoplakia PC BLUMBERGS, JF HALLPIKE, J MCCLURE

Germ cell tumours of childhood: a review of 137 cases HB MARSDEN, JILLIAN M BIRCH, R SWINDELL

Signet ring cell lymphoma: a rare variant of follicular lymphoma M HARRIS, B EYDEN, G READ

Terminal deoxynucleotidyl transferase activity in childhood and adult acute lymphoblastic leukaemia SJ PROCTOR, AM DICKINSON, B FAIL, W WALKER, $S$ SERISIER

Studies on blood lymphocytes of patients with nodular poorly differentiated lymphocytic lymphoma AS KRAJEWSKI, AE DEWAR

Comparison of liquid and dried sodium citrate as the anticoagulant for Thrombotest and prothrombin time estimations D HOCTOR, J BOTTOMLEY, K HYDE, AH GOWENLOCK, JE MACIVER
Requests for reprints to: Professor J Vandepitte, Department of Microbiology, St Raphaël University Hospital, B-3000 Leuven, Belgium.
Assay of serum immunoreactive trypsin in dried blood spots and the early detection of cystic fibrosis HC RYLEY, PG ROBINSON, Y YAMASHIRO, DM BRADLEY

Satisfactory screening for cystic fibrosis with the BM meconium procedure RT EVANS, AJ LITTLE, AE STEEL, JM LITTLEWOOD

Isolation of actinomycetes from cervical specimens RM TRAYNOR, D PARRATT, HELEN LD DUGUID, ID DUNCAN

Rapid identification of Corynebacterium vaginale in non-purulent vaginitis JI WELLS, SH GOEI

Group B streptococci-gastrointestinal organisms CSF EASMON, A TANNA, P MUNDAY, S DAWSON

A new serotype of calicivirus associated with an outbreak of gastroenteritis in a residential home for the elderly WD CUBITT, PJ PEAD, AA SAEED

Resistance to rifampicin and isoniazid in strains of Mycobacterium tuberculosis SH SIDDIQI, A AZIZ, $\mathrm{Z}$ REGGIARDO, G MIDDLEBROOK

Evaluation of ten commercial blood culture systems to isolate a pyridoxal-dependent streptococcus GS TILLOTSON

\section{Technical method}

In situ cytoenzymatic identification of human bone marrow colonies grown in agar: a simple method with automated cytochemistry reagents KG PATTERSON, DC LINCH, M ROSENDAAL

\section{Letters to the Editor}

Book reviews

Notices

The Association of Clinical Pathologists: 106th Scientific Meeting

Copies are still available and may be obtained from the PUBLISHING MANAGER, BRITISH MEDICAL ASSOCIATION, TAVISTOCK SQUARE, LONDON WC1H 9JR, price $£ 3.00$, including postage. 